\title{
Management of Contact of a Pregnant Woman with a Child Having Rubella
}

\section{Kıamıkçıklı çocuk ve Gebe Teması Yönetimi}

\author{
Mustafa Hacımustafaoğlu' ${ }^{1}$ \\ ' Department of Pediatrics, Department of Pediatric Infectious Diseases, Uludag University School of Medicine, Bursa, Turkey
}

Dr. İrem Civan, Dr. Fatih Korukçu, Dr. Elanur Subaşı

Question 1: Physician in the community health care center considered rubella in a child whose mother was one-month pregnant. What should be done?

Question 2: Is there a risk if a pregnant physician with MMR vaccination examines a child with rubella?

Question 3: Can pregnant healthcare professionals provide care for a child diagnosed with rubella but hospitalized for another reason?

Cite this article as: Hacımustafaoğlu M. Management of contact of a pregnant woman with a child having rubella. J Pediatr Inf 2019;13(1):e50-e53

\section{Answer (Dr. Mustafa Hacımustafaoğlu)}

The aforementioned questions and questions related to one another will be answered mutually.

Upon contact of a pregnant woman with a child having rubella or suspected to have rubella, maternal rubella infection can develop in the pregnant woman and can lead to congenital rubella syndrome (CRS), in other words fetal organ damage, by affecting the fetus. This problem can be essentially solved by having all woman vaccinated for rubella (1 dose) preconception or more preferably before marriage. As it is known, children are vaccinated routinely with two doses of rubella immunization (MMR: measles, mumps and rubella combination) in our country. It is readily seen that children with 2 doses of MMR vaccination will not face such a problem when they get older and married. Performing a routine rubella scan in pregnancy is recommended. It has been shown in a study conducted in our country that before routine MMR vaccination period, approximately $15 \%$ of the woman between $20-29$ years did not have rubella antibodies, which means that they are susceptible to rubella.

It should be kept in mind that any kind of infection that could develop in a pregnant woman and its management are under the responsibility of the obstetrician following the patient. When rubella infection is suspected in the pregnant woman, a thorough and scientific evaluation must be carried out and the family enlightened with the outcomes. Adult infection consultation would be appropriate to ask in necessary circumstances. A road map should be drawn following the opinion of the family. However, this question is frequently addressed to pediatricians and especially to physicians of pediatric infectious diseases in terms of definitive diagnosis and contagiousness. Moreover, diagnosis and monitoring of an infant that was born with suspected CRS are carried out by a pediatrician or a physician of pediatric infectious diseases. Therefore, it has been found appropriate to give general information on this matter.

Correspondence Address / Yazışma Adresi

Mustafa Hacımustafaoğlu

Uludağ Üniversitesi Tıp Fakültesi,

Çocuk Sağlığı ve Hastalıkları Anabilim Dalı,

Çocuk Enfeksiyon Hastalıkları Bilim Dalı,

Bursa-Türkiye

E-mail:mkemal@uludag.edu.tr

Received: 28.01.2019

Accepted: 06.02.2019 
Prior to giving answers to the aforementioned interrelated questions, this subject matter should be evaluated considering the pathogenesis, immunity, and contagiousness of the rubella infection, serological values of the mother and the child with whom contact was made, and the risk factors of the fetal infection. Thus, taking notice of some general information regarding rubella and maternal rubella infection would be beneficial.

Incubation period of rubella is generally accepted as 14-18 days (12-23 days), the disease is transmitted by direct contact or droplet infection. It is more commonly seen in late winter and early spring. Close and long-term contact with the infected persons make it easier to acquire the infection.

Viremia develops on $5^{\text {th }}-7^{\text {th }}$ days post-contact in rubella infection and spreads to different organs through blood. Rubella virus can be detected in nasopharyngeal samples one week prior to the appearance of the rash until two weeks after it. Maximal nasopharyngeal viral dissemination happens on the $5^{\text {th }}-7^{\text {th }}$ days after the onset of the rash.

In maternal rubella in the pregnant woman, maternal-fetal transmission occurs with hematogenous dissemination connected with the viremia in the mother and depends on the gestational age. First placenta infection, then fetal vascular system infection and vascular damage, cytopathic damage, and ischemia-induced organ damage develop with hematogenous dissemination, which leads to CRS.

While fetal infection rates in maternal primary rubella infection is $80 \%$ and over in the first trimester, they decrease to $25 \%$ in the last periods of the second trimester. However, these rates start to increase again in the third trimester (approximately $35 \%$ in the $27^{\text {th }}-30^{\text {th }}$ weeks; approximately $100 \%$ after the $36^{\text {th }}$ week). However, CRS is primarily observed in the first 16 weeks of pregnancy in maternal infection. Rubella infection which develops in the first 8-10 weeks of pregnancy leads to multiple fetal defects in $90 \%$ of the cases and may cause miscarriage, fetal death and still birth as well as CRS.

CRS shows totally different clinical findings than typical rubella (postnatal rubella). CRS is the most significant complication of rubella in a social level. Rubella leads to intrauterine rubella infection as a TORCH agent dependent on the measles infection that develops in susceptible pregnant women and may result in the birth of a child with CRS. Ophthalmologic (cataract, retinitis pigmentosa, microphthalmia, congenital glaucoma), cardiac (PDA, peripheral pulmonary artery stenosis), auditory (sensorineural deafness), neurologic (microcephaly, mental retardation, meningoencephalitis, behavioral disorders) manifestations and also growth retardation, interstitial pneumonia, radiolucent bone disease, hepatosplenomegaly, thrombocytopenia, dermal erythropoiesis (blueberry muffin lesion) can develop. Even though CRS is not expected after the $20^{\text {th }}$ week of pregnancy, fetal infections after the $20^{\text {th }}$ week of pregnancy are frequently in the form of intrauterine retarded development instead of CRS. Evidence towards pre-pregnancy or periconceptional period rubella infection causing CRS is not present and accepted.

If the mother has maternal immunity connected with natural infection or prior immunization, intrauterine rubella infection associated with maternal re-infection or CRS is not generally expected despite contact with a child with rubella. Although rare cases of maternal re-infection-related CRS have been reported, none of these are related to the infection after the $12^{\text {th }}$ week of pregnancy.

A child with rubella can be contagious 1-2 weeks prior to clinical findings and 7 days after the onset of rash, and thus droplet precautions are applied during this term in postnatal rubella infection.

Neutralizing antibodies start to develop with the onset of rash in rubella, and viral spread decreases. After rubella infection, specific lgM first starts to become positive after the $4^{\text {th }}$ day of rash and stays positive until 6-8 weeks of primary infection. Specific lgG starts to rise just a bit after IgM and stays positive for long years. It is thought that rubella-specific $T$ cell response develops approximately one week after humoral response and continues a lifetime.

IgM positivity should be interpreted with attention in cases with screening purposes carried out in societies where there is clinical findings, suspected contact, or low rubella infection incidence, the likelihood of false positivity should be kept in mind. In such cases, rise of IgG titer in double serum sample can be beneficial and IgG avidity should be checked. False positive lgM response can be seen in rheumatoid factor, parvovirus $\operatorname{lgM}$ and heterophile antibody positivity. While low-avidity lgG supports recent (new) primary rubella infection, the presence of high-avidity lgG supports past (old) infection or reinfection. High-avidity lgG antibody positivity or the fact that there is not an expected amount of increase in the double serum sample in IgG contributes in the evaluation of false lgM positivity.

Rubella vaccination normally provides effective protection. $\geq 95 \%$ seropositivity is expected from single-dose rubella vaccination and provides long term protection, which is strengthened by a second dose. Even if there is a decrease in rubella antibody levels that can be detectable, immunity related to vaccination can last a lifetime.

IgG antibodies are accepted as the indicator of protective immunity (vaccination or infection); however, there can be rare reinfections despite lgG positivity. Yet, it is not expected of the reinfection in the pregnant woman to form a risk to the 
intrauterine fetus. Generally, the fact that rubella specific lgG antibody concentration in serum is $>10 \mathrm{IU} / \mathrm{mL}$ is regarded as the serologic evidence of protection. Existing $\lg G$ titer rapidly increases in reinfection.

Diagnosis of acute rubella infection is made in the company of clinical findings or after contact with suitable incubation period (25-50\% of the cases can be asymptomatic): fourfold IgG titer increase in double serum sample (every 2-3 weeks), rubella specific lgM positivity or rubella virus culture positivity (PCR positivity).

Serologic samples provide insight best 7-10 days after rash and it is appropriate for their repetition 2-3 weeks later. Viral culture (or PCR) can be taken from the nose, throat, urine, blood, and BOS if necessary (from one week prior to rash until two weeks after).

In prenatal diagnosis for congenital rubella infection developing in the fetus, prenatal diagnostic approaches are as follows: PCR can be examined from the fetus in chorionic villus biopsy samples during $10^{\text {th }}-12^{\text {th }}$ weeks; in amniotic fluid samples during $14^{\text {th }}-16^{\text {th }}$ weeks; fetal blood samples during $18^{\text {th }}-20^{\text {th }}$ weeks. Diagnosis with ultrasonography is difficult in prenatal diagnosis of CRS and generally does not give an idea. As in all other congenital infections, intrauterine growth retardation can be detected in prenatal US.

Protective IgG administration (neither in the way of IM nor IVIG) after a susceptible person comes in contact with a patient with rubella is not recommended. As prophylactic lgG does not prevent infection or viremia, it can also repress symptoms and deteriorate serologic evaluation (especially lgG). Likewise, it has not been proven that post-contact rubella or MMR vaccination could prevent the disease.

Some factors need to be clarified in the management of a pregnant woman reporting contact with a child thought to have rubella;

1. Determining that the rubella diagnosis of the child with rash is definitive: Rubella rash can be mistaken to any other disease with rash. Vaccination status of the child and serologic condition should be identified. If there is rubella specific IgM positivity and increased lgG positivity in double serum samples in an unvaccinated child, the disease with rash is considered rubella in practice. A child proven not to have active rubella serologically (vaccinated child, rubella IgM negative, rubella IgG positive and IgG avidity high child) is not accepted as having rubella and the pregnant woman is not additionally managed for contact with patient with rubella.

2. Determining previous immunity of the pregnant woman: From the history and vaccination card of the pregnant woman, her vaccination status should be recorded and rubella specific $\lg M$ and $\lg G$ should be examined and repeated 2-3 weeks later if necessary. Serologic evaluation should be performed at the earliest. IgM negativity and IgG positivity show immunity related to vaccination or natural infection. Rubella reinfection can occur in a seropositive pregnant woman; however, CRS development is not expected and not seen after the $12^{\text {th }}$ week of pregnancy. In this perspective, it is important for all pregnant woman to have completed rubella vaccination, preferably as two doses of MMR, and to have immunization against rubella.

3. Determining the presence of rubella infection in the pregnant woman: In a previously unvaccinated and susceptible pregnant woman, IgM and IgG are examined after the suitable incubation period (approximately 2-3 weeks later) and repeated 2-3 weeks later. If possible, viral culture is performed. IgM positivity, increased IgG positivity in double serum sample, low IgG avidity and culture positivity, if possible, are accepted as proof of maternal infection in the pregnant woman even if there is no rash. If rubella infection is not detected in a susceptible pregnant woman, post-delivery MMR vaccination should be highly recommended.

4. Determining fetal risk according to the pregnancy phase if the pregnant woman has infection: As mentioned above, CRS risk is at the highest in the first 16 weeks in primary maternal infection (85\% in the first 12 weeks) and is not expected after the $20^{\text {th }}$ week. CRS risk is rare between the $16^{\text {th }}$ and $20^{\text {th }}$ weeks $(<\% 1)$ and is generally in the form of sensorineural deafness. These risks should be shared with the family and appropriate consultation be given. In advanced pregnancy phases, fetal response related to fetal infection is primarily in the form of intrauterine growth retardation. Fetal infection risk is very low even in the first trimester in maternal reinfection $(8 \%, 95 \% \mathrm{Cl} ; 2-22)$.

5. Determining fetal infection in risky maternal primary infection (prenatal diagnosis): As mentioned above, PCR can be examined from the fetus in cord virus samples during $10^{\text {th }}-12^{\text {th }}$ weeks; in amniotic fluid samples during $14^{\text {th }}-16^{\text {th }}$ weeks; fetal blood samples during $18^{\text {th }}-20^{\text {th }}$ weeks. Cord virus samples can be more advantageous for early detection. Even though ultrasound follow-ups are accrued out, they are not significant for prenatal specific diagnosis in rubella. If done, the family should be given consultation according to fetal risk status.

All in all, management of a pregnant woman in contact with a child with a preliminary diagnosis of rubella is closely related to the susceptibility of the pregnant woman to rubella and the age at pregnancy. Following meticulous evaluation of the pregnant woman in terms of proven rubella infection and outcomes, the family should be given appropriate consultation and a mutual understanding should be reached considering the decision of the family. 


\section{References}

1. Aksit S, Egemen A, Ozacar T, Kurugol Z, Keskinoglu P, Tasbakan M, et al. Rubella seroprevalence in an unvaccinated population in Izmir: recommendations for rubella vaccination in Turkey. Pediatr Infect Dis J 1999;18:577-80.

2. American Academy of Pediatrics. Rubella. In: Kimberlin DW, Brady MT, Jackson MA, Long SS (eds). Red Book: 2018-2021 Report of the Committee on Infectious Diseases. $31^{\text {st }}$ ed. Itasca, IL:American Academy of Pediatrics, 2018:705-11.

3. Cherry JD, Adachi K. Rubella virus. In: Cherry JD, Demmler-Harrison GJ, Feigin RD, Kaplan SL, Steinbach WJ, Hotez PJ (eds). Feigin and Cherry's Textbook of Pediatric Infectious Diseases. 7th ed. Philadelphia: Saunders Elsevier, 2014:2195-225.

4. WHO. Rubella vaccines: WHO position paper. Wkly Epidemiol Rec 2011;86:301-16.

5. Best JM. Rubella. Semin Fetal Neonatal Med 2007;12:182-92.

6. Webster WS. Teratogen update: congenital rubella. Teratology 1998;58:13-23.

7. Miller E, Cradock-Watson JE, Pollock TM. Consequences of confirmed maternal rubella at successive stages of pregnancy. Lancet 1982;2:781-4.

8. Morgan-Capner P, Miller E, Vurdien JE, Ramsay ME. Outcome of pregnancy after maternal reinfection with rubella. CDR (Lond Engl Rev) 1991; 1: R57-9.
9. Riley LE. Rubella in pregnancy. https://www.uptodate.com/contents/ rubella-in-pregnancy?search=rubella\&source $=$ search_result\&selecte$d T i t l e=3 \sim 150 \&$ usage_type $=d e f a u l t \& d i s p l a y \_r a n k=3$ (Accessed date: January 2019).

10. Enders G, Nickerl-Pacher U, Miller E, Cradock-Watson JE. Outcome of confirmed periconceptional maternal rubella. Lancet 1988;1:1445-7.

11. Dontigny L, Arsenault MY, Martel MJ;Clinical Practice Obstetrics Committee. Rubella in pregnancy. J Obstet Gynaecol Can 2008;30:152-8.

12. Robinson J, Lemay M, Vaudry WL. Congenital rubella after anticipated maternal immunity: two cases and a review of the literature. Pediatr Infect Dis J 1994;13:812-5.

13. Thomas HI, Morgan-Capner P, Cradock-Watson JE, Enders G, Best JM, $O$ 'Shea S. Slow maturation of IgG1 avidity and persistence of specific IgM in congenital rubella: implications for diagnosis and immunopathology. JMed Virol 1993:41:196-200.

14. Edwards MS, Hirsch MS, Bloom A (eds). Rubella. https://www.uptodate. com/contents/rubella (Accessed date: 17 December 2016).

15. Best JM, O'Shea S, Tipples G, Davies N, Al-Khusaiby SM, Krause A, et al. Interpretation of rubella serology in pregnancy--pitfalls and problems. BMJ 2002;325:147-8.

16. Skendzel LP. Rubella immunity: defining the level of protective antibody. Am J Clin Pathol 1996;106:170-4.

17. Bullens $D$, Smets $K$, Vanhaesebrouck $P$. Congenital rubella syndrome after maternal reinfection. Clin Pediatr (Phila) 2000;39:113-6. 